\title{
Experiència personal a l'escola d'estiu EduglobalSTEM: una història de pors, inseguretats, superació i empoderament.
}

\author{
Anna Mateo \\ Professora de física i química a l'institut Can Mas de Ripollet \\ amateo21@xtec.cat
}

\section{ABANS DE L'EEE19.}

Si baixo la mirada, no em preguntarà.

Sempre dic el què penso. No sempre s'ha considerat una virtut, però així ha estat. Quan una cosa no em sembla bé, ho dic. Però que sempre digui el que penso no significa que tothom en tingui notícia o que sàpiga que he sigut jo qui ho ha pensat.

Sempre recordaré aquells moments d'angoixa profunda quan algun professor o professora llançava una pregunta a l'aire (o en la meva direcció i sentit). La majoria de les vegades coneixia la resposta però, el simple fet de dir-la en veu alta, que tothom de la classe l'escoltés i el terror a equivocarme i quedar en evidència, em paralitzava. Moltes vegades, si m'asseia al costat d'alguna persona "més valenta que jo" li deia la resposta en veu baixa i aquesta l'exposava a la classe i s'emportava la felicitació del professorat. Encara que m'hagués agradat aquell reconeixement per part de l'adult, ja en tenia suficient: la meva idea havia arribat a la persona que volia que arribés i li havia agradat. No obstant això, a mesura que anaven passant els anys, aquest fet d'estar a l'ombra, de no ser vista, ja no m'anava tan bé. Volia dir les coses i que la gent m'escoltés, i volia emportar-me el reconeixement per la meva feina però aquell terror, aquell escalfament global del meu cos cada vegada que algú em preguntava o es dirigia directament a mi, seguia allà.

Quan em van proposar d'anar al grup de treball EduglobalSTEM, vaig pensar que seria una oportunitat d'aprenentatge que no podia deixar escapar i m'havia de posar en mode catió i unir-m'hi. Vaig sortir gairebé plorant de les dues primeres sessions. No perquè em tractessin malament, en absolut! Va ser perquè estava aclaparada.

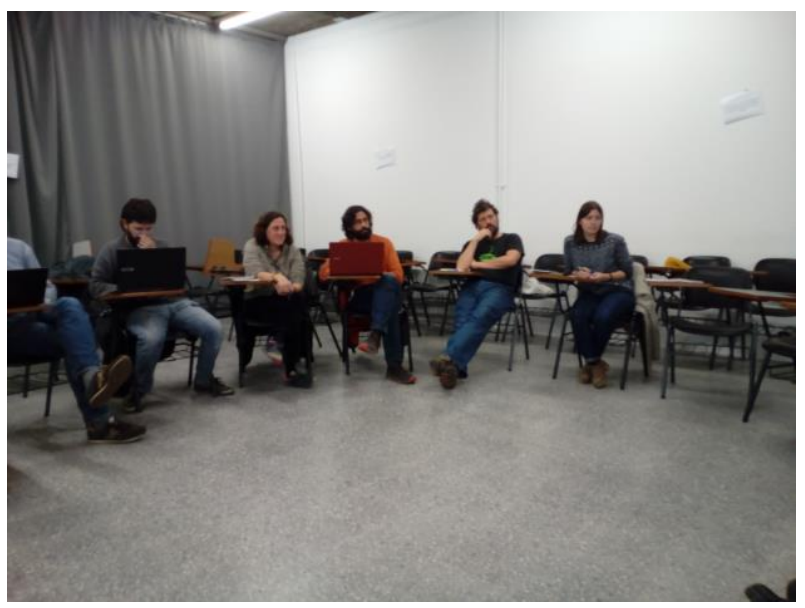

Figura 1: En una de les primeres reunions del grup de treball EduglobalSTEM (20/11/2018).

Allà hi havia gent que en sap molt, que té una experiència d'anys tant en docència com en justícia global (encara que deien que no...). I jo amb ells i elles, en el primer any al món de la docència encara amb trossos de closca d'ou per sobre el meu cos. Em sentia petita. No és que sigui molt gran físicament, això ja ho vaig superar fa temps, em refereixo a petita en sentit figurat. Què podia dir o fer en aquell grup? Què hi podia aportar? Em sentia una mera espectadora, no veia el motiu d'estar amb aquelles persones que en sabien tant. Apuntava tot el que podia (bàsicament paraules que no coneixia i que buscava al diccionari en arribar a casa) i procurava no parlar gaire per passar el més desapercebuda possible.

Van arribar les vacances d'hivern i ens van posar de deures fer "píndoles": petites comunicacions en format "fàcil de digerir" sobre coses que estàvem llegint o aprenent. Vaig fer un vídeo "a lo youtuber" sobre el llibre que estava llegint en aquell moment: 
"Intel-ligència emocional" de Daniel Goleman. Com gairebé sempre, estava satisfeta de la meva feina però, abans de fer-la pública davant del grup, vaig buscar l'aprovació privada del Felip Lorenzo (el meu tutor de les pràctiques del màster $\mathrm{i}$ qui em va introduir en aquest grup de treball). La meva sorpresa va ser quan vaig veure la seva reacció! I no només la seva! Quan el vam mostrar al grup van voler fer un canal de YouTube (https://www.youtube.com/channel/UCE7ZaeCgAM YPS_t3MzXrlLw) i ja m'estaven demanant el segon vídeo. No estava acostumada a aquest reconeixement: l'escalf i les suors van estar presents tota l'estona. No obstant això, alguna cosa havia canviat: ja no sortia mig plorant de les sessions, sinó satisfeta i amb un petit somriure d'orgull.

Va arribar llavors el moment de començar a preparar la primera escola d'estiu d'EduglobalSTEM (l'EEE19) que, per descomptat, creia que em venia gran. Una altra vegada van tornar els dubtes. Una escola per a "profes" i jo he de dir-los què han de fer? Però com se m'acudeix participar en una cosa així! Si vivia molt tranquil.la.

No va ser casualitat que, quan vaig haver d'escollir un ponent per fer-li d'amfitriona, la meva elecció va ser el David Bueno: professor i investigador de genètica a la Universitat de Barcelona i divulgador científic. El seu treball està centrat en la formació del sistema nerviós i en la seva relació amb la conducta i els processos d'aprenentatge.

Quan vaig llegir el seu llibre "Neurociència per educadors" i vaig descobrir tot el que deia sobre la mirada dels educadors, la motivació i la creativitat i les neurones mirall (Bueno, 2017), tot el núvol d'idees sobre com hem d'ensenyar, quin mètode és el millor, etc., va caure de cop. No vull criticar el meu professorat, van fer el que bonament van poder, el que creien que era el més efectiu i a molts els recordo amb molt d'afecte, però la manera de plantejar i aplicar aquell sistema educatiu va tenir un efecte devastador en el meu desenvolupament tant a classe com a la vida. No em van donar l'oportunitat de ser jo mateixa o, com a mínim, no ho van potenciar. En el moment en què el meu grup de treball em va encomanar una tasca i em va donar la llibertat per fer-la com volgués, vaig sentir-me jo, em vaig trobar còmoda, segura i el resultat va ser molt satisfactori. Potser la manera com em mirava el professorat, amb aquell prejudici (moltes vegades involuntari) i l'etiqueta que sentia que em posaven no deixava que fes el pas endavant i pogués parlar amb més facilitat davant la classe? Potser el fet que les tasques i feines s'haguessin de fer d'una manera molt determinada, sense donar peu a la meva creativitat i les meves fortaleses, no em van deixar ser jo mateixa i em van fer sentir insegura? Potser el comportament del professorat, ja sigui per ser massa estricte o massa distès 0 , sobretot, massa autoritari va fer que tingués més por a quedar en evidència per no saber alguna cosa? Potser sí.

\section{DURANT L'EEE19.}

\section{Primers dies: Un pas endavant en primera persona.}

Ja ha arribat el primer dia de l'EEE19. Estic nerviosa. La meva tasca és la de donar la benvinguda al professorat que s'ha apuntat al curs. Identifico immediatament a la gent jove i novella (com jo). Tenen aquella mirada amb un xic de por però a la vegada motivada i amb ganes d'aprendre. També hi veig gent amb un tarannà que m'intimida (i en són la majoria): l'experiència. Ai mare, on m'he ficat.

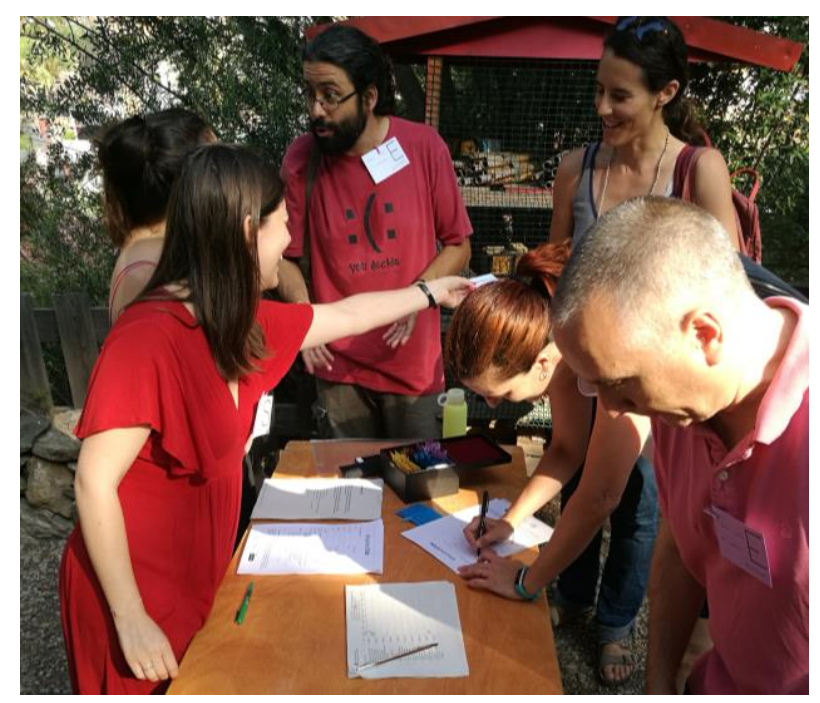

Figura 2: Donant la benvinguda als nous "eduglobals" a l'EEE19 (01/07/2019).

La Marina Caireta ens presenta. Jo observo la gent com l'escolta i començo a decidir quin serà el meu paper en aquesta escola. Potser és millor deixar que el temps vagi passant, ajudar en el que pugui i deixar que els meus companys i companyes facin allò que tan bé saben fer. Ens posem per grups per presentar el que hem fet durant el curs. No parlo gaire, només una mica per no quedar malament i no semblar un moble. Bàsicament observo, una habilitat que he anat perfeccionant al llarg dels anys (si no parles, observes i, molt sovint, aquestes observacions donen molta informació que a d'altres els passa desapercebuda; desapercebuda com jo, com tot aquell alumnat "invisible" que sembla que no té cap problema, que no té res a dir). I què observo? $\mathrm{Hi}$ ha una majoria de dones al curs (exactament, hi 
ha un $73,5 \%$ de dones). Potser ha estat casualitat... però ho dubto. Hi ha una majoria de dones, sí, però sento moltes veus d'home, potser més veus d'home que de dona. Penso que no està bé: no pot ser que nosaltres, les persones que servim de referent al futur, que ens preocupem per la nostra tasca docent i que ens formem sobre justícia global, estiguem caient en un dels estereotips de gènere més bàsics. Penso en el llibre del David Bueno i el que explica de les neurones mirall: si diem que tothom és igual però no ens ho creiem i no actuem en conseqüència, l'alumnat tampoc ho farà. Ho penso i ho he de dir.

El meu pla és buscar, com quan era a l'institut, algú que ho faci per mi. A tothom li sembla una bona idea però estan molt ocupats, l'escola d'estiu dóna molta feina. Ho he de fer jo, ho he de dir jo, he de dir a aquesta gent molt més experta que no ho està fent bé. Què necessito? Motivació, creativitat i donar exemple. Tinc una bona motivació: la profunda creença què ningú no és millor pel fet de ser d'un sexe, gènere, orientació sexual, estatus social, cultura o color diferent, a més de fer visible el comportament esbiaixat que estic observant. He de buscar una manera de dir-ho que sigui efectiva però "suau" a la vegada i, evidentment, ho he de dir jo per predicar amb l'exemple. Els participants del curs, després del descans per menjar alguna cosa, hem de presentar les nostres propostes amb les aportacions que han fet els grups pels que han anat passant i se m'acudeix fixar-me bé en qui surt a parlar de cada grup, qui parla primer i cronometrar el temps que parla cadascú i, sense cap sorpresa, els resultats em donen la raó.

Comença el segon dia de l'EEE19. Avui ve la Yayo Herrero: antropòloga, enginyera tècnica agrícola, educadora social, professora, investigadora i activista ecofeminista. Tot un referent, $i$ jo he de fer la meva presentació sobre estereotips de gènere. Estic a punt de patir un infart. $\mathrm{He}$ fet uns gràfics on mostro les dades recollides en la sessió del dia anterior. Els gràfics parlen per ells mateixos.

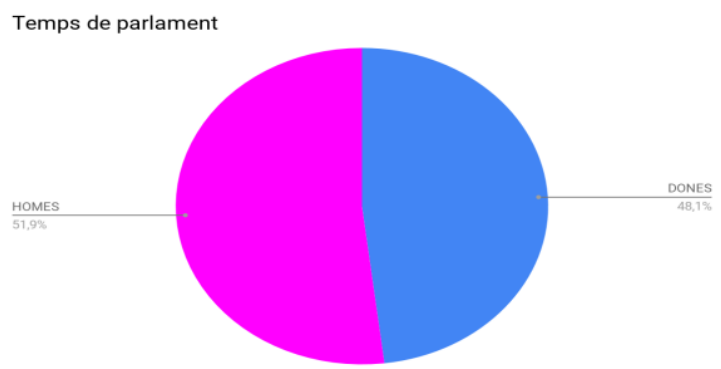

Figura 3: El gràfic del temps de parlament que es va presentar al grup: homes $51,9 \%$ (color rosa) i dones 48,1\% (color blau). EEE19 (02/07/2019). Vídeo de la presentació: primers 7 minuts

https://www.youtube.com/watch?v=EBoDBKaOdzA
Veig la gent inquieta, està funcionant i ara la Yayo rematarà la feina amb el seu discurs. Em sento bé: hi ha gent que se m'acosta a comentar els gràfics durant el descans, m'expliquen situacions similars que han viscut i observat altres vegades. Hi ha qui intenta donar alguna explicació, com si volgués disculpar-se, i hi ha qui agraeix la coherència del curs amb les actuacions del grup. A més, durant aquesta i les pròximes sessions es veu un canvi substancial en el comportament d'homes i dones. Ha estat tot un èxit!

Últims dies: l'empoderament.

El meu cervell va fer un "clic". De sobte em sentia totalment integrada al grup de gent que tenia al voltant. Havia aportat alguna cosa i, a més, una cosa important gràcies a una habilitat: l'observació. Ningú no m'ho va demanar, simplement en vaig tenir la necessitat i això em va motivar prou per poder portar-ho a terme. El tercer dia venia el "meu" ponent: el David Bueno. Les meves companyes i companys del grup em van dir que aquell dia va ser el que menys activa vaig estar, però estaven molt equivocats: el meu cervell anava a mil per hora. Com diu el David, el cervell, quan aprèn, necessita un temps per poder assimilar els aprenentatges i és quan badem que el nostre cervell és més actiu en aquest procés (Bueno, 2019). I el meu cervell havia après molt, moltíssim, i necessitava badar. Aquell dia semblava que no hi fos. Ja havia llegit el llibre del David però mentre l'escoltava, sense voler (o volent), em va fer reflexionar sobre tot el que m'havia passat.

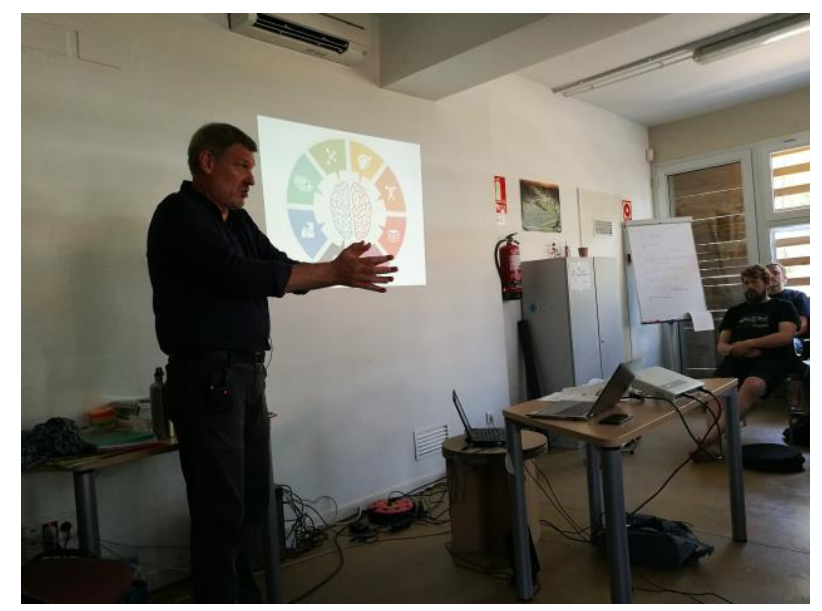

Figura 4: El David Bueno fent el seu discurs el tercer dia de l'EEE19 (03/07/2019)

Quan ens parlava de com la mirada del professorat pot influir en l'alumnat vaig pensar en com em miraven a mi. Sabien que era tímida i que per això no parlava gaire però no acostumaven a animar-me o motivar-me perquè no tingués aquesta 
por. Simplement l'acceptaven (com ho feia jo) i procuraven no fer-me sentir malament, no em preguntaven què necessitava. Després, el David va parlar de les neurones mirall, ens va dir que som un referent per al nostre alumnat i que hem de tenir una actitud "d'aprendre junts" i no de "jo vinc a ensenyar". És en aquell moment que em van venir al cap les meves inseguretats, la por a quedar en evidència, la meva paralització quan estic entre persones que saben més que jo. El David continuava explicant: com han de ser les activitats per predisposar a l'alumnat? "Obertes i creatives: que permetin a tothom aportar i aprendre, que els permeti identificar-se". No sé si riure o plorar. Quanta raó! I, per acabar, l'explosió cerebral final: "una de les millors motivacions és crear una necessitat". Estava tot dit.

Els últims dies del curs vaig sentir-me com a casa. No hi era per ajudar, hi era per actuar. Tenia la sensació que podia fer qualsevol cosa. La meva vergonya i la meva por es van esfumar com l'electró del sodi quan s'acosta el clor. I, perquè entengueu millor com em sentia, us posaré un exemple molt il.lustratiu: a la sala del Bosc Turull, on fèiem el curs, hi feia molta calor i hi havia un ventilador. L'últim dia del curs, en passar pel davant del ventilador, el meu vestit es va aixecar una mica. En qualsevol altre instant de la meva vida això hauria produït una reacció catalítica al meu cos, fent que em posés vermella i m'amagués en algun racó on no em veiés ningú durant unes quantes hores. Però en comptes d'això, vaig riure, vaig fer broma i, fins i tot, vam fer un vídeo! Estava relaxada. Una cosa no havia sortit bé, però no m'ho vaig prendre com si hagués quedat en evidència davant de tothom sinó com una oportunitat d'aprendre (vigila quan passis pel davant del ventilador) i, a més, m’ho vaig passar bé.

\section{DESPRÉS DE L'EEE19.}

\section{Amb els peus a terra}

Després de la ressaca de l'escola d'estiu, van tornar una mica aquestes sensacions d'inseguretat $\mathrm{i}$ de por. Evidentment, el cervell no aprèn tan ràpidament com ens agradaria, però és veritat que van tornar més febles. Alguna cosa sí que havia canviat en mi, en la manera d'afrontar els problemes i reptes que em proposa la vida. Tot aquest aprenentatge que havia fet, tot aquest canvi que el grup i el curs van provocar en mi, havia de servir per poder ajudar el meu alumnat. És cert que, durant el meu primer any de docència, vaig caure en el parany dels prejudicis. Acceptava "la manera de ser" de cada estudiant i feia exactament el que feien els meus professors i professores amb mi: sentir compassió pels diferents problemes del meu alumnat i intentar no perjudicar-lo per aquest comportament però sense actuar d'una manera directa. Ja en tenia prou amb preparar les classes. Així que era jo qui decidia com podia ajudar cada alumne i alumna o els donava consells però no intentava enfocar la meva pràctica docent $i$ les meves activitats a les seves necessitats reals. Com era d'esperar, no crec que ajudés amb molta profunditat aquelles persones.

Ara procuro que, tot $\mathrm{i}$ donar instruccions explícites i ben detallades sobre les activitats i els objectius d'aquestes, les tasques que proposo al meu alumnat siguin el més obertes possibles perquè puguin sentir-se més còmodes realitzant-les i les puguin portar al seu terreny. I la veritat és que funciona. L'alumnat s'ho passa millor, està més motivat $i$ relaxat $i$ la cara que posen quan els descobreixo algun talent ocult i el poso en valor no té preu.

Crec que aquesta experiència que he tingut, ja sent adulta, l'he d'utilitzar (que no imposar) per poder ajudar més eficientment al meu alumnat, per comprendre millor què és el que senten, per entendre els seus problemes i per empoderar-lo. També crec que tothom que es dedica a l'activitat docent o té relació amb infants $\mathrm{i}$ adolescents ha tingut a la seva vida alguna experiència similar a la d'algun dels seus alumnes i pot ser molt més empàtic. No tothom té les mateixes vivències i per això és important que la tasca docent no sigui una tasca individual sinó col-lectiva per poder arribar a tot l'alumnat i, d'aquesta manera, sempre hi haurà algú que pugui ajudar aquell estudiant amb problemes.

Des del meu punt de vista, la tasca del docent és una de les feines més gratificants que existeixen. Hem de fer que el nostre alumnat estigui còmode, relaxat, no classificar-lo i intentar que pugui ser creatiu, que tothom tingui l'oportunitat de demostrar allò que millor sap fer. L'orgull de veure com creixen i es fan millors persones és immens. I tot resulta molt més fàcil quan ens posem a la seva pell perquè, al principi, tots i totes vam necessitar algú que ens donés l'empenta, algú que ens digués que podíem fer-ho perquè, al principi, tots $\mathrm{i}$ totes vam ser adolescents. 


\section{BIBLIOGRAFIA.}

Bueno, D. (2017). Neurociència per a educadors. (3a ed.). Barcelona: Octaedro.

Bueno, D. (2019). El cervell adolescent: com aprenen els adolescents?. Primera escola d'estiu EduglobalSTEM. Grup de treball EduglobalSTEM, Barcelona. https://vimeo.com/375845052. 